$09.1 ; 09.7 ; 10.2 ; 14.2$

\title{
Акустооптическая вейвлет-обработка биоэлектрических сигналов
}

\author{
(C) К.В. Зайченко, Б.С. Гуревич \\ Институт аналитического приборостроения РАН, Санкт-Петербург, Россия \\ E-mail: kvz24@mail.ru
}

Поступило в Редакцию 9 августа 2021 г.

В окончательной редакции 24 сентября 2021 г.

Принято к публикации 24 сентября 2021 г.

Одним из эффективных методов исследования характеристик информационных сигналов является их вейвлет-анализ. Впервые показана возможность вейвлет-обработки информационных сигналов на акустооптическом процессоре с временны́м интегрированием. Обоснована реализация на таком процессоре как вычисления спектра мощности, так и осуществления вейвлет-преобразования биоэлектрических сигналов в реальном масштабе времени. Приведен анализ, описывающий его работу в различных режимах.

Ключевые слова: вейвлет-анализ, биоэлектрические сигналы, акустооптические процессоры, временно́е интегрирование.

DOI: 10.21883/PJTF.2022.01.51877.18988

В последнее время вейвлет-анализ находит широкое применение в практике теоретических и прикладных научных исследований. При этом наибольшее развитие получили цифровые методы реализации вейвлет-анализа. Однако часто встречаются задачи, требующие обработки информационных сигналов в реальном масштабе времени. Такую возможность обеспечивают разработанные оптические вейвлет-процессоры корреляционного типа, снабженные набором вейвлет-фильтров [1-4]. Процедуры оптической обработки при этом предусматривают либо голографическую запись, преимущественно методами динамической голографии [2], либо запись изображений с использованием различных типов пространственных модуляторов света $[3,4]$.

Использование акустооптических (AО) технологий для вейвлет-анализа было впервые предложено в оптических устройствах обработки изображений при неразрушающем контроле изделий [5]. При этом акустооптический модулятор выполняет вспомогательную функцию ввода данных в оптический процессор, который реализует вейвлет-преобразование.

Постановка и решение задачи, которой посвящена настоящая работа, были вызваны необходимостью информационного обеспечения экспериментальных исследований процессов развития искусственных патологий у подопытных животных на основе авторского метода инструментальной электрофизиологии сверхвысокого разрешения, которые проводит наша лаборатория „Радио- и оптоэлектронные приборы ранней диагностики патологий живых систем“ ИАП РАН совместно с физиологами Института экспериментальной медицины Федерального центра им. В.А. Алмазова [6]. В реальном времени потребовалось вычислять спектр мощности и осуществлять вейвлет-преобразование исследуемых биоэлектрических сигналов (БЭС), что в специфических условиях эксперимента можно осуществить лишь с использованием безынерционных АО-процессоров.
Поскольку обычные АО-устройства работают с сигналами частотой порядка десятков-сотен мегагерц, анализ на них низкочастотных БЭС потребовал реализации особых методов их обработки [7], в частности с использованием акустооптического спектроанализатора с временны́м интегрированием для вычисления в реальном времени спектра мощности данных сигналов [8]. Оптическая схема этого устройства представлена на рисунке.

Эта оптическая схема включает в себя две встречно ориентированные ячейки Брэгга, на одну из которых подается сигнал с линейной частотной модуляцией (ЛЧМ-сигнал), промодулированный по амплитуде информационным сигналом $s_{1}(t)$, а на другую - опорный ЛЧМ-сигнал $s_{2}(t)$ с прямоугольной огибающей. Линзы обеспечивают оптическое преобразование Фурье, а режекторный фильтр исключает нулевой дифракционный порядок. Многоэлементный линейный фотоприемник

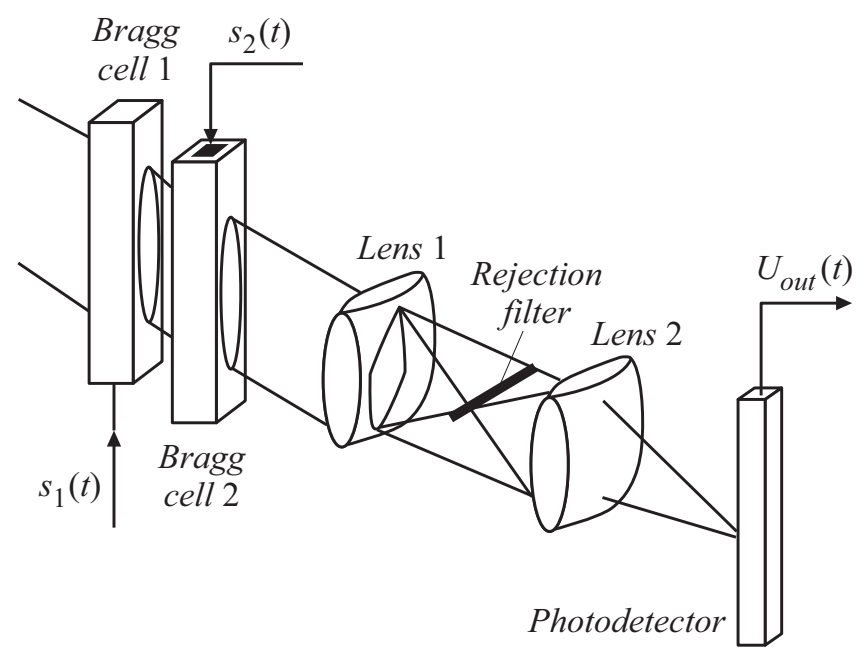

Оптическая схема акустооптического спектроанализатора с временны́м интегрированием. 
обеспечивает накопление заряда и формирует выходной сигнал.

Поскольку вейвлет-анализ на акустооптике до сих пор не проводился, потребовалось искать пути к его реализации. Само вейвлет-преобразование по определению представляет собой свертку анализируемой функции времени $s_{1}(t)$ и функции материнского вейвлета $s_{2}(t)$, что описывается формулой

$$
W_{f}(a, b)=\frac{1}{\sqrt{|a|}} \int_{-\infty}^{\infty} s_{1}(t) s_{2}^{*}\left(\frac{t-b}{a}\right) d t,
$$

где $a$ и $b-$ параметры, определяющие масштаб и временной сдвиг функции $s_{2}(t)$ относительно информационного сигнала $s_{1}(t)$ (звездочка означает комплексное сопряжение) [9]. Выяснилось, что впервые операцию свертки с помощью АО-процессора с временнб́м интегрированием предложил осуществлять Монтгомери, который защитил свое техническое решение патентом США [10]. Схема конвольвера Монтгомери рассмотрена и обоснована в $[11,12]$. Она оказалась идентичной схеме, показанной на рисунке.

Согласно [11], результирующая интенсивность света $I_{d}$ в плоскости многоэлементного линейного фотоприемника может быть записана как

$$
\begin{aligned}
I_{d}(x, t) & =\left|i(1 / 2) \tilde{s}_{1}\left(t-\frac{x}{v}\right)+i(1 / 2) \tilde{s}_{2}\left(t+\frac{x}{v}-T_{a}\right)\right|^{2} \\
& =\frac{1}{4}\left|\tilde{s}_{1}\left(t-\frac{x}{v}\right)\right|^{2}+\frac{1}{4}\left|\tilde{s}_{2}\left(t+\frac{x}{v}-T_{a}\right)\right|^{2} \\
& +\frac{1}{2} \operatorname{Re}\left\{\tilde{s}_{1}^{*}\left(t-\frac{x}{v}\right) \tilde{s}_{2}\left(t+\frac{x}{v}-T_{a}\right)\right\},
\end{aligned}
$$

где $\tilde{s}$ означает комплексный аналитический сигнал, $x-$ координата в ячейках Брэгга и в фотоприемнике, $v-$ скорость звука в среде звукопровода, $T_{a}-$ временна́я апертура ячейки Брэгга. На выходе фотоприемника формируется заряд, который пропорционален энергии падающего света за время засветки и ограничивается допустимым временем интегрирования линейки. Эта энергия равна

$$
\begin{aligned}
E(x) & =\frac{1}{4} \int_{T}\left[\left[\operatorname{Re} \tilde{s}_{1}^{*}\left(t-\frac{x}{v}\right)\right]^{2} d t\right. \\
& +\frac{1}{4} \int_{T}\left[\operatorname{Re} \tilde{s}_{2}\left(t+\frac{x}{v}-T_{a}\right)\right]^{2} d t \\
& +\frac{1}{2} \operatorname{Re}\left\{\int_{T} \tilde{s}_{1}^{*}\left(t-\frac{x}{v}\right) \tilde{s}_{2}\left(t+\frac{x}{v}-T_{a}\right) d t\right\} .
\end{aligned}
$$

Первые два члена уравнения (3) являются постоянными при достаточно большом времени интегрирования $T$, а третий член представляет собой свертку функций $s_{1}(t)$ и $s_{2}(t)$.
Приведенные выше данные позволили нам предложить использование конвольвера с временны́м интегрированием $[10,11]$ для реализации вейвлет-преобразования информационного сигнала $s_{1}(t)$ как его свертку с его материнским вейвлетом $s_{2}(t)$.

Точно такая же, как на рисунке, схема AO-процессора с временнб́м интегрированием приведена в [13] для получения спектра информационного сигнала $s_{1}(t)$. Работа этой схемы подробно рассмотрена в [14]. В ней описаны такие же ЛЧМ-сигналы, как в схеме, представленной на рисунке, которые подаются на ячейки Брэгга:

$$
\begin{gathered}
s_{1}^{\prime}(t)=\left[1+s_{1}(t)\right] \cos \left(\Omega_{0} t+0.5 \gamma t^{2}\right), \\
s_{2}^{\prime}(t)=\cos \left(\Omega_{0} t+0.5 \gamma t^{2}\right),
\end{gathered}
$$

где $s_{1}^{\prime}(t)$ представляет собой ЛЧМ-сигнал с начальной частотой $\Omega_{0}$ и крутизной частотной модуляции $\gamma$, промодулированный по амплитуде информационным сигналом $s_{1}(t) ; s_{2}^{\prime}(t)-$ опорный ЛЧМ-сигнал с прямоугольной огибающей. Там же [14] показано, что комплексные огибающие этих сигналов имеют вид

$$
\dot{u}_{s_{1}^{\prime}}(t)=\left[1+s_{1}(t)\right] \exp \left(i 0.5 \gamma t^{2}\right), \dot{u}_{s_{2}^{\prime}}(t)=\exp \left(i 0.5 \gamma t^{2}\right) .
$$

Как и в случае конвольвера, на выходе фотоприемника формируется заряд, пропорциональный энергии падающего света. Если отфильтровать постоянный пьедестал, то можно выделить сигнальную составляющую накопленного в фотоприемнике заряда [14]:

$$
\begin{aligned}
& Q(x)=\operatorname{Re}\left\{A \exp \left(i 2 K_{0} x\right) \int_{L / v}^{L / v+T} \dot{u}_{s_{1}^{\prime}}\left(t-\frac{x}{v}\right) \dot{u}_{s_{2}^{\prime}}^{*}\left(t+\frac{x}{v}\right) d t\right\} \\
& =\operatorname{Re}\left\{A \exp \left(i 2 K_{0} x\right) \int_{L / v}^{L / v+T} s_{1}\left(t+\frac{x}{v}\right) \exp \left(-i \frac{2 \gamma x t}{v}\right) d t\right\},
\end{aligned}
$$

где $K_{0}=\Omega_{0} / v, L-$ размер линейной апертуры акустооптической ячейки. Из выражения (6) следует, что накопленный заряд на фотоприемнике (его распределение по координате $x$ ) представляет собой спектр сигнала $s_{1}(t)$ на несущей пространственной частоте. Таким образом, рассматриваемая схема при подаче на нее соответствующих сигналов реализует формирование спектра информационного сигнала $s_{1}(t)$.

В конвольвере Монтгомери $[10,11]$ предусмотрен ввод радиочастотных сигналов $s_{1}(t)$ и $s_{2}(t)$ в соответствующие две ячейки Брэгга для формирования их свертки, что позволило нам предложить реализацию вейвлетпреобразования информационного сигнала (3). На этой основе можно реализовать вейвлет-обработку биоэлектрического сигнала, используя амплитудную модуляцию радиочастотных несущих в обеих ячейках Брэгга (см. рисунок) информационным БЭС и его материнским вейвлетом. В этом случае по аналогии с (5) и (6) 
выходной сигнал вейвлет-процессора-конвольвера может быть представлен в виде

$Q(x)=\operatorname{Re}\left\{A \exp \left(i 2 K_{0} x\right) \int_{L / v}^{L / v+T} s_{1}\left(t+\frac{x}{v}\right) s_{2}\left(t-\frac{x}{v}\right) d t\right\}+C$,

где $C$ - пьедестал с переменной амплитудой. Следовательно, при использовании несущих радиочастотных сигналов накопленный заряд на CCD-линейке несет информацию о вейвлет-преобразовании сигнала $s_{1}(t)$ по материнскому вейвлету $s_{2}(t)$.

В результате доказана возможность на одном AO-процессоре с временны́м интегрированием (см. рисунок) проводить вычисление как вейвлет-преобразования информационного сигнала $s_{1}(t)$, так и его спектра мощности.

Таким образом, в работе впервые показана возможность вейвлет-обработки информационных сигналов на акустооптическом процессоре с временны́м интегрированием, а также обоснована реализация на таком процессоре при подаче на его входы различных сигналов как вычисления спектра, так и осуществления вейвлетпреобразования БЭС в реальном масштабе времени. Это представляет интерес для многих практических приложений.

\section{Финансирование работы}

Работа поддержана Министерством науки и высшего образования РФ (государственное задание № 0750078019-00, тема 0061-2019-0017).

\section{Конфликт интересов}

Авторы заявляют, что у них нет конфликта интересов.

\section{Список литературы}

[1] V. Petrun'kin, E. Aksyonov, G. Starikov, Proc. SPIE, 4680, 212 (2002). DOI: $10.1117 / 12.454687$

[2] A. VanderLugt, Optical signal processing (Wiley Interscience, N.Y., 1991).

[3] W. Feng, Y. Yan, G. Jin, M. Wu, Q. He, Proc. SPIE, 3804, 249 (1999). DOI: 10.1117/12.363971

[4] Y. Wang, L. Ma, S. Shi, Opt. Commun., 204, 107 (2002). DOI: $10.1016 / \mathrm{S} 0030-4018(02) 01246-4$

[5] C.M. DeCusatis, J. Koay, D.M. Litynsky, P.K. Das, Proc. SPIE, 2643, 17 (1995). DOI: 10.1117/12.222751

[6] К.В. Зайченко, А.А. Кордюкова, Е.П. Логачев, М.Н. Лучкова, Медицинская техника, № 1, 21 (2021). [K.V. Zaichenko, A.A. Kordyukova, E.P. Logachev, M.N. Luchkova, Biomed. Eng., 55 (1), 31 (2021). DOI: 10.1007/s10527-021-10065-3].

[7] Г.М. Аристархов, Ю.В. Гуляев, В.Ф. Дмитриев, К.В. Зайченко, В.В. Комаров, Фильтрация и спектральный анализ радиосигналов. Алгоритмы, структуры, устройства (Радиотехника, М., 2020), с. 18-48.

DOI: $10.18127 / \mathrm{B} 9785931082028$
[8] K.V. Zaichenko, B.S. Gurevich, Proc. SPIE, 11075, 110751 U (2019). DOI: $10.1117 / 12.2535709$

[9] И. Добеши. Десять лекций по вейвлетам (НИЦ „Регулярная и стохастическая динамика“, Ижевск, 2001), с. 115.

[10] R.M. Montgomery, US. Patent 3634749 (1972).

[11] W.T. Rhodes, Proc. IEEE, 69, 65 (1981). DOI: 10.1109/PROC.1981.11921

[12] В.Н. Ушаков, Акустооптические процессоры корреляционного типа (Радиотехника, М., 2007), с. 56-68.

[13] T.M. Turpin, Proc. IEEE, 69, 79 (1981). DOI: 10.1109/PROC.1981.11922

[14] В.В. Проклов, В.Н. Ушаков, Акустооптические процессоры спектрального типа (Радиотехника, М., 2012), c. $65-71$. 